\title{
CHAPTER 85
}

\section{A SYSTEMS APPROACH \\ TO PETROLEUM PORT SITE SELECTION}

\author{
William s. Gaither \\ Associate Professor of Civil Engineering \\ University of Delaware, Newark, Delaware (Ref. 1) \\ and \\ J. Patrıck Sides \\ Engineer, Collen Brothers Ltd., East Wall \\ Dublin, Ireland (Ref. 2)
}

\section{ABSTRACT}

Petroleum port site selection is examined in the broad context of the total transportation system from production to consumption area. Basic systems englneerıng approaches are applied to the problem to formulate a mathematical model which permlts all transportation system variables, including capltal and operating costs, to be put in quantitative form. An example of the computer solution is given, along with a discussion of the principal calculations involved. Unit transportation cost is selected as the measure of effectiveness of candidate systems. The port site associated with the system yielding the lowest unit transportation cost for the entire range of throughputs is selected.

\section{INTRODUCTION}

O11 and many other natural resources are found in areas of the world far from the centers of consumption. Many alternate routes exist between the points of production and consumption; however, only one route, with the optimum mix of vehicles, permits the lowest cost transportation of the commodity.

The great tankers of today often cannot use the sheltered ports frequented by general cargo vessels, and must be moored on an exposed coast where depth and maneuvering room are adequate. Thus oil port site selection no longer represents a choice between a few natural harbors, but rather is a matter of identifying an optimum transportation system and adapting a point on the coast to permit ship loading or discharging. The basic question confronting an engineer-economist responsible for port site selection is how to locate that site, or family of sites, through which petroleum can be transported at the lowest cost.

The systems approach enforces orderly thought and is adaptable to any level of study effort, ranging from a cursory review, to the precise economic comparison of several fully designed systems. Of particular significance is that the systems approach requires that the engineer recognize and examine the entire petroleum transportation system of which the port site is only one part.

This paper examines in successive steps: (1) the basic systems engineering approach, (2) the elements of petroleum transportation systems, (3) systems engineering applied to petroleum port site selection, and (4) a mathematical model for choosing one port site from anong several candidates. 


\section{BASIC SYSTEMS ENGINEERING APPROACH}

A commercial need, such as moving crude oil from a producing field to a refinery and then to the consumer, results in the conception of a system which will satisfy the need both technically and economically. This system may be defined in terms of specific objectives which must be met and also specific constraints which must be observed. Both the objectives and the constraints can be distilled into what can be termed system requirements which become the inputs to various alternate schemes.

Following the determination of system requirements, alternate approaches are developed to satisfy the requirements. In other words how to attain the stated objectives while respecting the limitations of the constraints.

Next a trade-off study, or economic comparison, is conducted to choose the most promising approaches from among all of those proposed. A simple mathematical model is used which accounts for system cost and performance. In some cases only one approach is technically feasible while in other cases many approaches, with nearly equal merıt, may be Identified. Each scheme which shows technical and economic promise is carried through a preliminary desıgn phase so that all of Its parameters may be put in quantitative form. Thls reqires that both capital costs and operating costs be defined by the system design.

The evaluation of these candidate systems is made on the basis of a measure of effectiveness. This measure of effectiveness is the independent variable of an economic function, or mathematical model, which permits all other system parameters to be expressed as dependent variables. It 18 essential that this type of study recognize and account for all performance and cost effects of a system design alternative. On this basis the most effective of the candidate systems is selected, resulting in a cholce which may be defended both economically and technically.

\section{THE ELEMENTS OF PETROLEUM TRANSPORTATION}

The systems engineering approach requires consideration of all parts of the total transportation system which change with different harbor sites and requires understanding of both the technical and economic aspects of various modes of petroleun transportation and their interrelationships.

\section{TRANSPORTATION MODES}

Generally, petroleum is moved from the producing field to the consumer by a series of transportation modes. These modes are selected on the basis of economy and are normally pipelines on land and large tankers at sea. Since pipelines provide a continuous flow and ships operate as batch carriers, it is necessary to provide a surge, or storage, capability between these two modes to achieve maximum economy in the system. The size of this storage facility, or tank farm, is determined by the number of products handled, by the method of product segregation, and the regularity with which tankers arrive and depart.

A second important difference between these two widely used modes of crude oil transport is that with an increase in throughput, tankers can be added on an individual basis as required, but that a pipeline of specific diameter and wall thickness must be installed initially.

Each transportation mode and its intervening surge facility may be thought of as a series of separate, but interdependent, links which make up the total petroleum transportation system. 


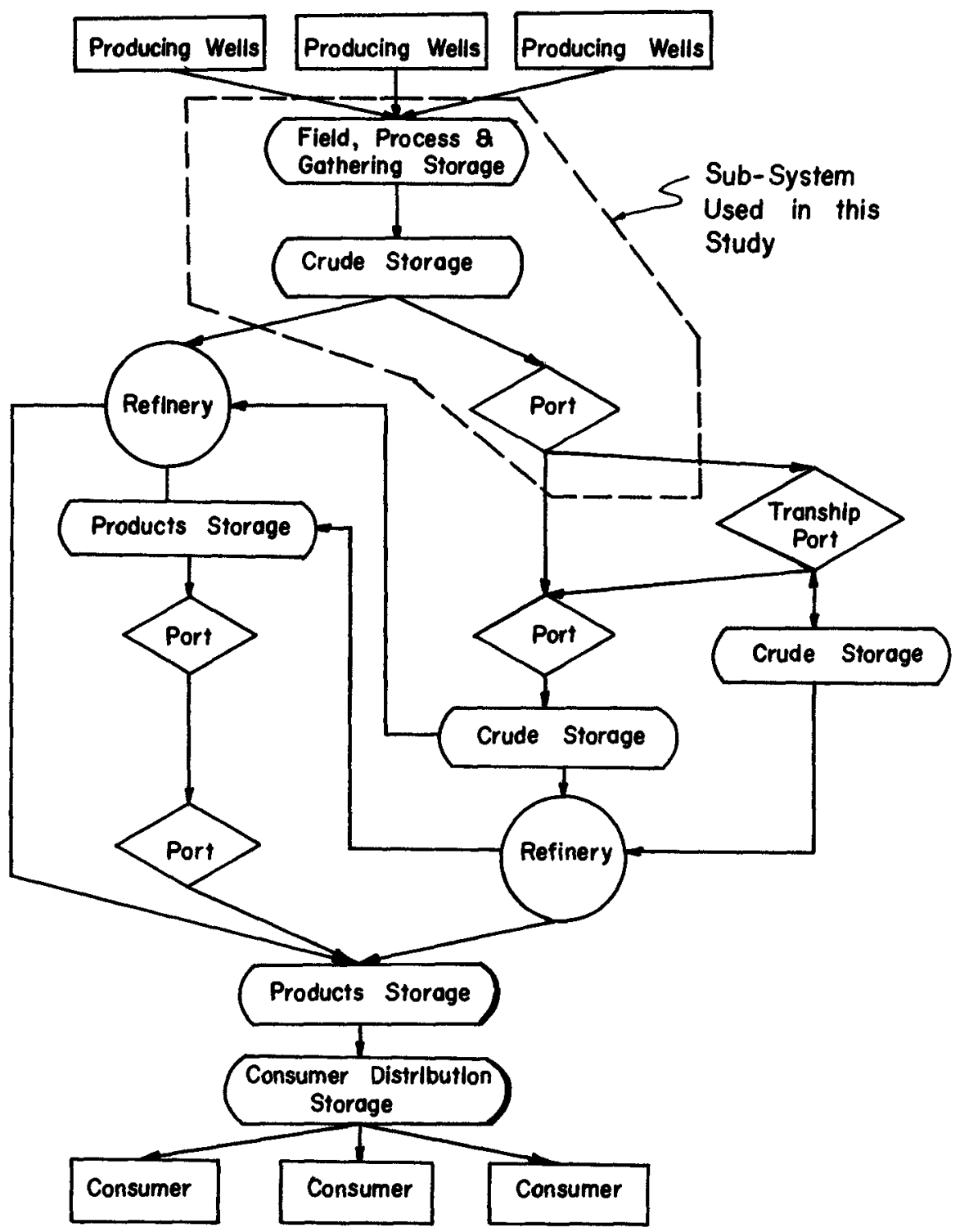

Figure 1

GENERALIZED OIL TRANSPORTATION SYSTEM 


\section{THE GENERALIZED SYSTEM}

A generalized 011 transportation system is shown schematically in Figure 1, from well head to the consumption point, indicating transportation modes and interfaces. The interfaces are either points where one form of transport is exchanged for another or where there is an interruption in flow. Ports, storage tanks and refineries are all interfaces. A port is an example of a change in transportation mode, while field gathering storage is an interruption in the flow along a pipeline.

Crude is pumped from well head to field gathering storage, where gas may be separated from the crude or different crudes mixed together before being transported further. The crude then moves on to an intermediate storage facility before being pumped to a port for shipment by tanker or being piped to a refinery for processing. If oil tankers are used, the oil is unloaded at the port of destination to a tank farm before being pumped to a refinery. With the advent of the very large tankers, which are limited to a few very deep ports, the use of the trans-shipment port has become more prevalent. At a trans-shipment port the oll is off-loaded from the large tanker into smaller tankers and the excess pumped to storage; or if no smaller tankers are present, a11 the oil is pumped to storage to await thelr arrival. Alternatively, some of this crude can continue its journey to a refinery by pipeline or other forms of transport. From the refinery the product goes into product storage from which it is distributed, by any of the transportation modes, to the various consumption points.

Figure 1 can thus be used to identify the oil transportation system for any given situation. In a transportation system in which oil tankers are used, the choice of different routes is based mainly on consideration of possible port sites and on possible land transportation routes. Sea routes have also to be considered but they are much more flexible than land routes. If 1 t is required to select a particular facility within a transportation system, such as a port site, it is probably not necessary to analyze the entire transportation system, but only part, or sub-system. The sub-system study described as an example in this paper is indicated on Figure 1.

\section{SYSTEMS ENGINEERING APPLIED TO PETROLEUM PORT SITE SELECTION}

The fundamental problem to be solved is how best to move o11 from the area of production to the area of consumption. The systems approach provides a logical step by step process whereby the most efficient and economical method of oil transportation can be found. The port which 1 s chosen after such a study may not require the least initial investment or be the least expensive to operate of the candidate port sites, but the transportation system of which 1 t is a part w111 provide the most economical method of o1 1 transportation from producer to consumer. Figure 2 is a flow diagram showing the steps by which a systems study of this type is carried out.

\section{OBJECTIVES AND CONSTRATNTS}

The oll port, like all other parts of the system, must be designed to meet the objectıves of the entire system. These objectives normally include a definition of (a) the orıgin and destination of the petroleum, (b) inctal and ultimate throughputs of the system, (c) anticipated rates of system growth, (d) the time scale for construction and start up, and (e) the useful life of the system.

Varıous types of constraints must also be recognized at the outset of 


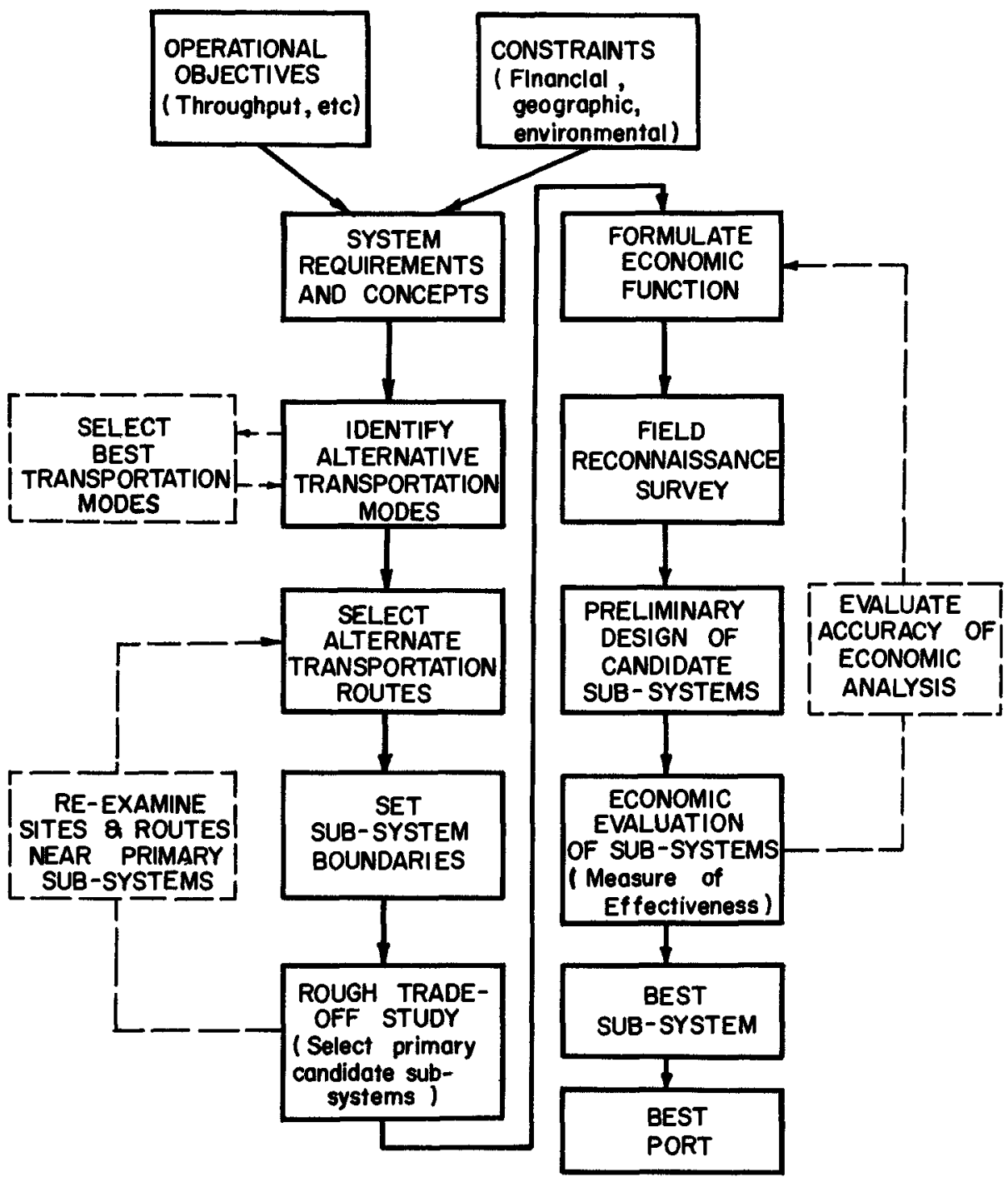

Figure 2

FLOW DIAGRAM FOR SYSTEMS

APPROACH TO HARBOR SITE SELECTION 
the study. These constraints may be thought of in the broader context of the system "environment". The environment can be broken down into technical, economic, and social environments. The technical environment covers existing oil transportation systems and their technical obsolescence, the present state of technology as it applies to oil transportation, and expected or possible developments in oil transportation. This would, for example, include a study of very large tankers in the 200,000 to 1,000,000 DWT range and methods of mooring, loading and unloading their oil.

The economic environment is concerned with costs of existing and projected systems, unit costs of material and labor, and changing customers and markets. Since the transportation system chosen must operate for a number of years, it must be designed with the flexibility to accomodate possible changes in throughput and consumption areas.

Within the social environment are considered the possible effects of changing political climates on the operation of the system, and the advantages of operating in one country rather than another.

\section{SYSTEM REQUIREMENTS}

Under the heading of system requirements all objectives and constraints are distilled into a compatible performance criteria for each part of the system. In this step the scope of the total system is established and the general type of route from origin to destination is identified.

\section{ALTERNATIVE TRANSPORTATION MODES}

There will be a number of transportation modes (1.e. tankers, pipelınes, railcars, etc.) which may be used to move the oll. These modes are now considered and alternative combinations which satisfy the system requirements are chosen. In this case, one of these modes will be a form of ocean transport requiring a port. The alternative modes are then assessed by making a rough cut trade-off study based on the applicability of the transportation mode to the terrain and its use cost. In the case used in this paper, the modes are pipelines and ocean going tankers.

\section{TRANSPORTATION ROUTES}

There are theoretically an infinite number of different routes between the production and consumption areas. Practically, however, only those routes which appear technically feasible are chosen. This choice will normally be made by experienced people using available topographic maps and hydrographic charts. Each port site may be served by several sea routes and also by several pipelines routes. Every different combination, even though passing through the same port site, represents a separate transportation route.

\section{SUB-SYSTEMS}

For the purpose of port site selection it may only be necessary to consider part of the total transportation system. It is probable that geographic or national boundaries have placed several constraints on the candidate systems and that all systems pass some common (or nodal) point such as a strait, pass, canal, or cape which may, for study purposes, be regarded as the terminal point of a sub-transportation system. If such sub-systems are in fact independent of the total transportation system they may be used for the optimization study and as a consequence permit a substanital reduction in field investigation, preliminary design, and economic analysis efforts 
Figure 3 shows the transportation sub-system discussed in this paper, and which is shown schematically in Figure 1. The sub-system used as a basis for this optimization study has as its upstream nodal point the field gathering facilities. Proceeding downstream, the sub-system contains the following

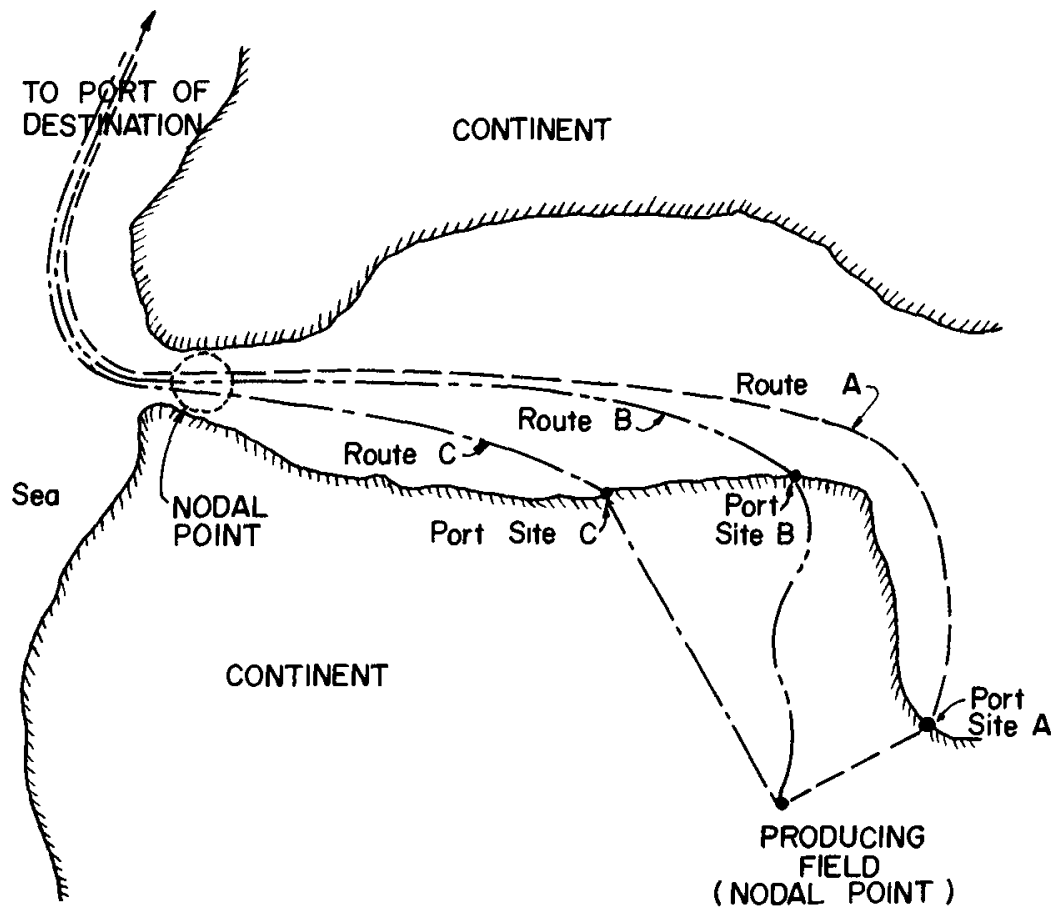

Figure 3

\section{ALTERNATE PETROLEUM TRANSPORTATION ROUTES}

links: (1) pipeline, (2) tank farm at the marine terminal, (3) high capacity ship loading lines, (4) the harbor and ship loading berths, and (5) a sea voyage to the downstream nodal point. This nodal point is designated as the nearest point to the candidate harbor sites which all ships pass.

The accuracy required in setting the boundaries, or nodal points, of the sub-systems depends on the accuracy required of the study. In the case of oil port site selection, the transportation route is analyzed both upstream and downstream from the port site until those points are identified which are common to all sub-systems and such that the consideration of any candidate port site has no effect on those portions of the transportation system outside the sub-system boundaries. 


\title{
ROUGH TRADE-OFF STUDY
}

Once the candidate sub-systems have been Identified a rough trade-off study can be used to eliminate those which are grossly non-competitive. Subsystems considered in this paper are compared in Figure 4. Each sub-system has been assigned five cost variables which represent the links in the subsystem including: (a) pipeline (b) tank farm, (c) harbor, (d) sea voyage, and (e) unusual operating costs. The last item is used to convert any unique annual costs not common to all sub-systems into a capital cost.

\section{PRELIMINARY EVALUATION OF CANDIDATE SUB-SYSTEMS (CAPITAL COST BASIS IN MILLIONS OF DOLLARS ) ( FOR ANTICIPATED MEDIAN THROUGHPUT)}

\begin{tabular}{|c|c|c|c|c|c|c|c|}
\hline SUB-SYSTEM & PIPELINE & $\begin{array}{c}\text { TANK } \\
\text { FARM }\end{array}$ & HARBOR & VOYA & $\begin{array}{c}\text { UNUSUAL } \\
\text { OPERATING } \\
\text { COSTS }\end{array}$ & $\begin{array}{c}\text { SUB-SYSTEM } \\
\text { COST }\end{array}$ & $\begin{array}{c}\text { SELECTED } \\
\text { PRIMARY } \\
\text { CANDIDATES }\end{array}$ \\
\hline A & 50 & 9 & 6 & 2 & - & 67 & Yes \\
\hline B & 120 & 10 & 6 & 2 & 1 & 139 & No \\
\hline C & 150 & 8 & 7 & 2 & 2 & 169 & No \\
\hline D & 55 & 10 & 7 & 3 & - & 75 & Yes \\
\hline E & 70 & 9 & 5 & 3 & 1 & 88 & Yes \\
\hline ETC & & & & & & & ETC \\
\hline
\end{tabular}

\author{
Figure 4 \\ ROUGH TRADE-OFF STUDY MATRIX
}

Th1s simple comparison of the candidate sub-systems shows that due to high pipeline costs for systems $B$ and $C$ neither could be competitive with $A, D$, and $E$ even though the assigned costs are only approximate. Those subsystems with the lowest costs are selected as primary candidates for more detailed economic comparison.

\section{THE ECONOMIC FUNCTION}

At this point in the study it is desirable to formulate the economic function which will be used in a more precise trade-off study for the comparison of the primary candidate sub-systems. This method of selection requires a mathematical model, though it may be quite simple, which reflects the influence of two types of quantifiable parameters -- one related to system performance, and the other related to system cost. The accuracy of the study rests in the degree to which all parameters are quantifiable, although it is occasionally necessary to use quasi-quantifiable inputs.

The purpose of this procedure is to set forth systematically the parameters which affect the rational selection of port site under the present, and foreseeable, conditions of system operation. A key part of the trade-off study is the selection of a Measure of Effectiveness (MOE) of all the system design alternatives. The Unit Transportation Cost (UTC), expressed in say dollars per ton, is a measure of effectiveness which permits all other 
varıables in a petroleum transportation system, or sub-system, to be expressed as dependent variables in a single economic function. It is essential that this type of study recognize and account for all performance and cost effects of a design alternative.

The economic function

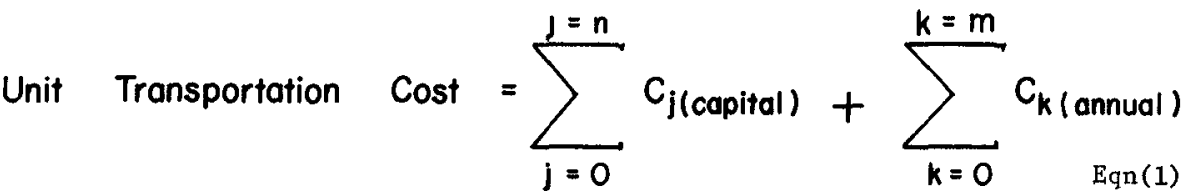

contains $(n)$ capital cost terms $\left(C_{j}\right)$ and $(m)$ annual cost terms $\left(C_{k}\right)$, each representing a quantifiable feature of a candidate sub-system. This economic function should be established before undertaking the design of the candidate sub-systems since it identifies the significant cost parameters. The economic importance of each term should be determined early in the study so that the fleld investigation and design effort can be devoted to the items which have the greatest inpact on the UTC.

\section{Accuracy of the Economic Function}

At this stage in the study it is also possible to examine each term of the economic function and make a preliminary estimate of the accuracy with which each can be evaluated. From this the potential range of inaccuracy, or error, of the UTC can be established and in turn the required accuracy of all terms of the economic function can be set.

\section{Comparitive vs Absolute Economic Studies}

It should also be declded whether the UTC is to represent the absolute costs of a sub-system or whether its purpose is only to compare similar systems. If absolute UTC's are desired all cost items of each system must be represented by a cost term in the economic function. If comparative UTC's are required, as is the case if port site selection is the only objective, all equal cost terms comon to each candidate sub-system may be omitted from the economic function. The omission of these common terms will reduce the amount of effort required to complete the study.

It should be noted that Equation (1) represents a steady-state condition for a given increment of system expansion. Its formulation should not be confused with a dynamic analysis which examines the state of the transportation system at uniform increments of time or at each event.

\section{FIELD RECONNAISSANCE SURVEY}

A field reconnalssance survey is normally necessary before beginning the preliminary sub-system design phase, particularly when the candidate routes and sites are located in an unfamiliar part of the world. The first step is to conduct a rough trade-off study as shown in Figure 4, so that only the several most promising sub-systems are retained for further investigation. The second step is to formulate the economic function to identify all significant cost items associated with the sub-systems being compared. The field reconnaissance survey can then be planned to concentrate on those features of the candidate sub-systems which represent the Items of greatest cost and about which the least is known. 
Typical reconnaissance surveys involve continuous selsmic profıling at harbor sites to determine marine soll conditions, estimates of quantities of littoral drift, scattered borings in the tank farm area to appralse foundation conditions, and low level flying of the pipeline routes to determine elevations and assess the types of material to be excavated in pipelıne burial. Data is also collected on local costs and availability of material and labor, duties, taxes, etc.

\section{DESIGN OF PRIMARY CANDIDATE SUB-SYSTEMS}

Each candidate sub-system, with its attendant port site, must be carried through a preliminary design phase in sufficient detail to permit all major cost items to be quantified.

\section{Criteria}

The first step in the preliminary design phase consists of establishing specific engineering criteria for both design and operation. Thls is contrasted to the general system performance criteria formulated at the beginning of the study.

\section{ENGINEERING DESIGN CRITERIA}

Candidate sub-systems were selected on the basis of rough order-ofmagnitude estimates of the physical size of the harbor and tank farm area needed to accomodate the ultimate throughput of the system. As a supplement to this selection criteria it is necessary to establish further englneering criteria so that alternate preliminary designs can be prepared for each port site. Typical items for which criteria wlll be required are average shlp size, maximum shlp size, water depths, ship turnıng radil, typical pier conflguratıon, typical breakwater cross-sections, storage tank sizes, and ship loading rates. Since several types of loading facilities (1.e. fixed plers, sea berths and mono-moorings) may be considered for each candidate site, it is necessary to establish comparable sets of criteria for each.

\section{OPERATIONAL CRITERIA}

Each alternate route and port site must be studies to determine what environmental characteristics will affect its performance uniquely. Overland and sea transportation routes will be affected by temperature extremes and storms. Port sites are particularly sensitive to wind and wave conditions which delay docking or require ships to leave a berth during loading or unloading operations. For each type of harbor development considered, separate criteria must be established for maximum permussible wave height and wind velocity. In comparing the effects of weather conditions on alternate port sites, a quantifiable parameter is that of port closure.

A ship turnaround time must be established which is compatible with demurrage-free time in port and with ship loading rates. Deballasting time and loading equipment capacity must also be selected to be compatible with ship turnaround.

\section{Harbor Design}

Crude oil and petroleum products are normally loaded or discharged across a fixed pier or through hoses to the ship in a sea mooring. Fixed piers may either be in a moderately exposed location or in a horbor sheltered by a breakwater. Sea berths are of either the spread mooring type where the ship rides to the center of a set of fixed lines, or the mono-mooring type where the ship "weather vanes" behind a single point bow attachment. All of these types of 
berth designs have different operational requirements and thus will show economic differences at each candidate port site.

In general it can be sald that a pier and breakwater design will show a high inftial UTC since the first cost of a breakwater is great in relation to the throughput of the port. This assumes that the ultimate harbor area is enclosed initially. As the throughput increases with system expansion to the UTC will drop due to both the greater volume of petroleum shlpped and also the minimal weather delays affecting a shelter harbor.

The sea berth and mono-mooring harbors will be closed by storms more often than a sheltered harbor, however their UTC's may be lower due to their installation cost. Also, sea berths and mono-moorings can be installed as needed in the course of system expansion instead of requiring a high early investment as in the case of a harbor sheltered by a breakwater. A small craft harbor to accomodate tugs and line running launches is needed in any event.

Port closure criteria assigned to these three types of harbor installation will normally take the following form:

\begin{tabular}{lrr}
\multicolumn{1}{c}{ Type of Harbor } & Max. Wave & $\frac{\text { Max. Wind }}{40 \text { knots }}$ \\
Piers with Breakwater & 15 feet & 20 knots \\
Sea Berths & 5 feet & 30 knots \\
Mono-moorings & 5 feet &
\end{tabular}

Thus piers sheltered behind a breakwater can be expected to operate under more severe conditions. The sea berth, on the other hand, is hampered

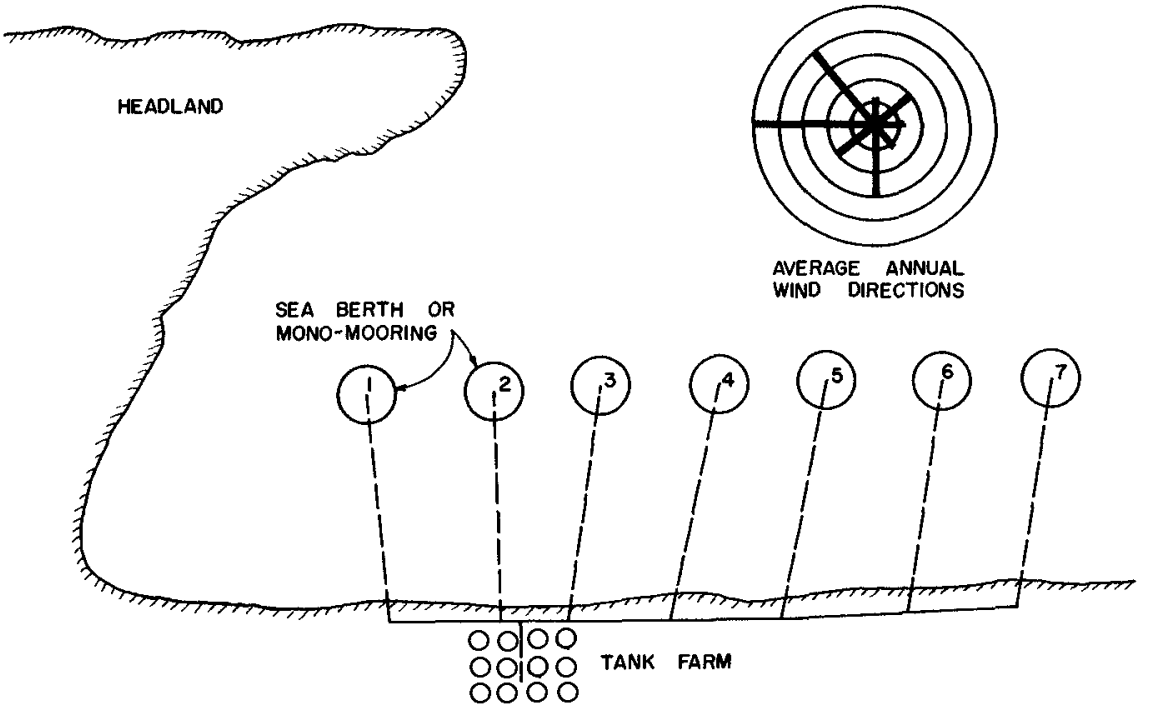

Figure 5

TYPICAL HARBOR EXPANSION PLAN 
by small waves due to the Inability of 11ne running launches to work in heavy seas and high winds; beam winds particularly may force the ship to leave the berth. The mono-mooring is also hampered by small waves since it must be served by line running launches but it can remain in the berth longer in high winds due to its ability to "weather vane" behind the mooring buoy.

Figure 5 shows a typical harbor expansion plan for sea berths or monomoorings. If we assume that this port site is exposed to local fetches and thus the wind and wave directions are approximately identical, it can be seen that substantial protection is afforded berth No.1 by protruding headland and that protection decreases along the coast through berth No.7. This then means that berth No.1 will be closed least because wind or waves exceeded the operational limit and that berth No.7 will be closed the most.

\section{Pipeline Design}

A pipeline is a part of a petroleum transportation system which represents a high initial investment and which is relatively inflexible once installed. The sub-system used for the study described in this paper includes a pipeline which delivers crude oll to the port. Thus pipeline design is an integral part of the system design.

Pipeline size is normally determined by the anticipated ultimate throughput of the system. Figure 6 shows a typical ground surface profile and hy-

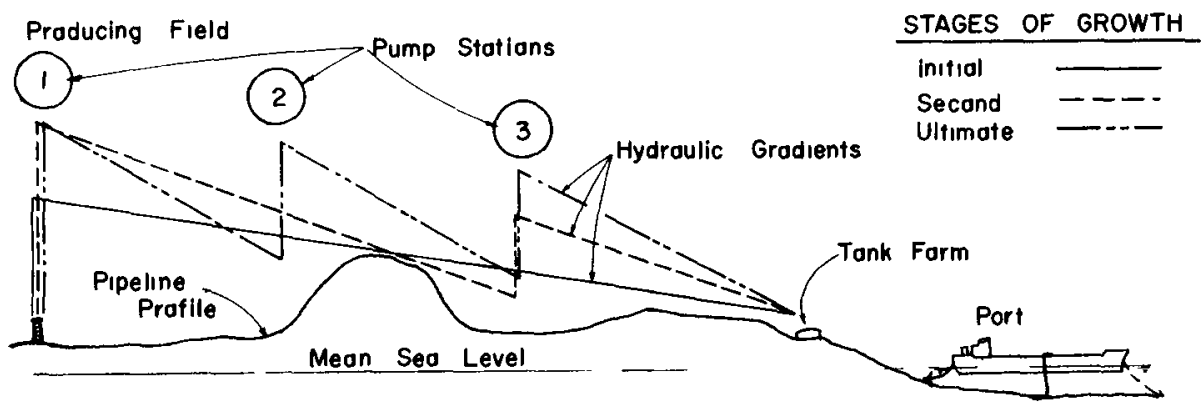

Figure 6

SCHEMATIC OVERLAND PIPELINE PROFILE

draulic gradients at several increments of system expansion. The initial system consists of the pipeline, Pump Station No.1 at the producing field, and a tank farm at the marine terminal. The hydraulic gradient decreases uniformly from Pump Station No. 1 at the producing field to the tank farm. Normally, the hydraulic gradient is kept above the ground surface thus maintaining a positive pressure in the line at all points.

The second stage of growth requires that Pump Station No.3 be installed and that additional horsepower be installed at Station No.1. The hydraulic gradient steepens between stations due to velocity head losses. Ultimate expansion 15 shown in the third state with the addition of Pump Station No.2 and increasing horsepower in Station No.3. 


\section{INCREMENTAL EXPANSION OF SYSTEM}

Oil transportation systems are seldom constructed to handle the1r ultimate capacity initially but rather to be expanded in several increments. The engineering design of each candidate system must be based on incremental expansion of the system, recognizing that falling reserves or marketing considerations could curtail expansion at any intermediate stage.

An 011 harbor can be enlarged by adding more berths, a tank farm by adding more storage tanks, and pipeline capacity by adding more pump stations. On the other hand, some parts of the system must be built initially to accommodate the ultimate throughput of the system. Typical of such parts would be pipeline diameter and wall thickness.

All engineering design for study purposes should be carried out on the basis of incremental expansion. Engineering quantities can then be associated with a given throughput of the system.

\section{Tank Farm and Loading Lines}

Designs in detail similar to those carried out for the harbor and pipeline portion of the sub-system must also be completed for the tank farms and loading lines. Factors which must be considered are land cost, number of different crudes to be handled, tanker loading rates, pumping requirements, and the availabillty of labor and local utilities.

\section{Review of the Economic Function}

Sub-system desıgn may reveal significant features which were not properly represented in the economic function. Upon completion of the design phase, the mathematical model should be reviewed to be certain that all items are adequately described. This can be readily accomplished by completing the material quantity take off for each increment of sub-system expansion since each quantity must be represented by a term in the economic function.

\section{A MATHEMATICAL MODEL FOR CHOOSING BETWEEN ALTERNATE PORT SITES}

The economic function of Equation (1) is the mathematical model which is used to select the "best" sub-system and 1ts attendant port site. While it is not mandatory that the economic function be programmed for a digital computer, investigation of incrementa1 growth and design alternates makes 1 ts use quite desirable in all but the most elementary cases. This paper assumes that the iterative capabilities of a digital computer will be employed in the lllustrative example which follows.

\section{ORGANIZATION OF ANALYSIS}

Figure 7 shows a descriptive computer flow dlagram which is designed to analyze the type of sub-system discussed in this paper (i.e. pipeline, tank farm, loading lines, and harbor). It requires as inputs the general data applicable to all systems, quantity data for each sub-system on an incremental basis, unit cost data for both capital and annual costs, and the initial and ultimate system throughputs.

The program then computes the unit transportation cost for each designated increment (usually $1 / 10$ or 1/20 of range between initial and ultimate) of throughput for each candidate sub-system. The output may be either printed or plotted as graphs. 


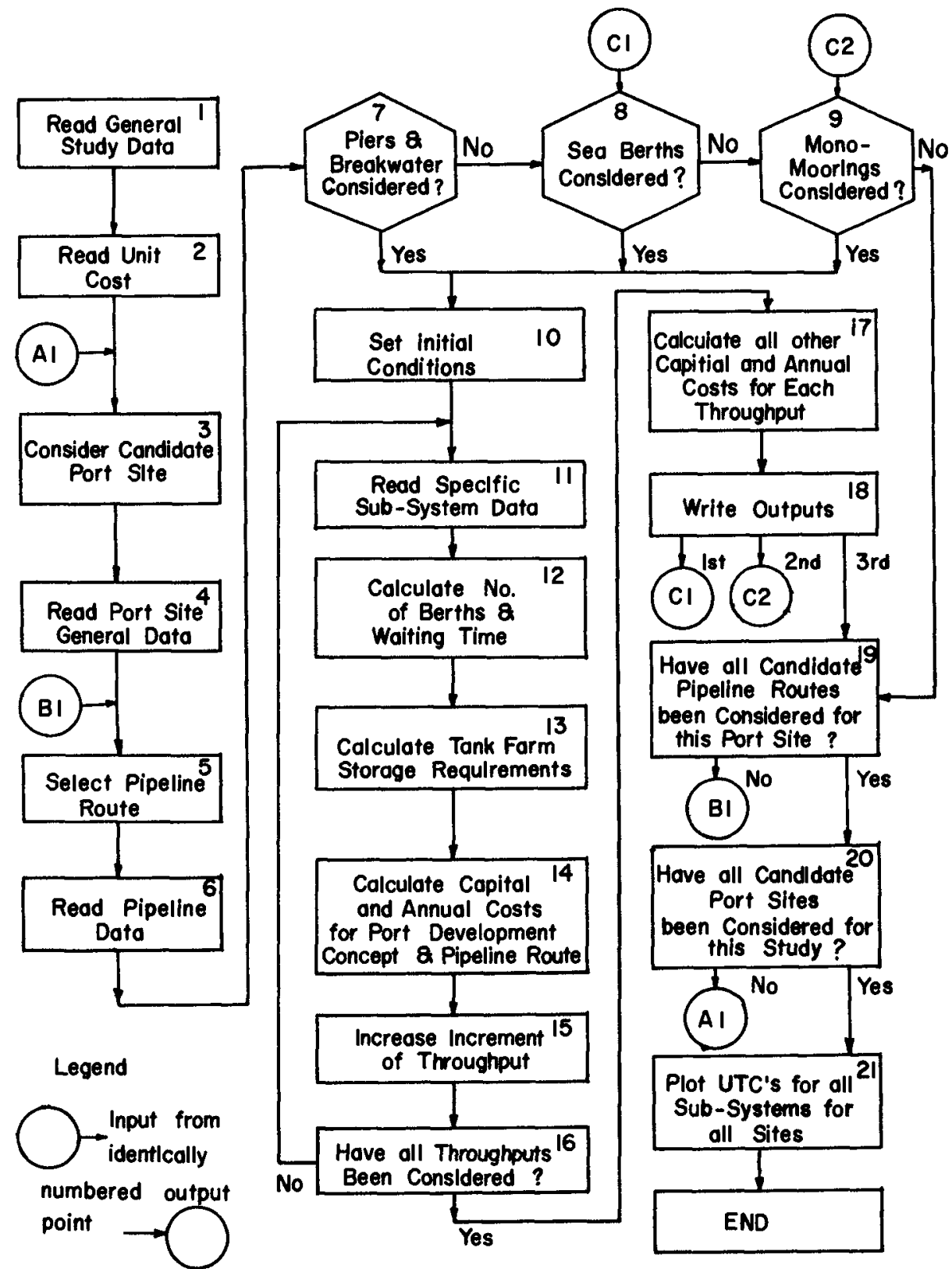

Figure 7

DESCRIPTIVE COMPUTER FLOW DIAGRAM 
The following sections describe the principal features of the programmed mathematical model and the basis of important computations.

\section{GENERAL INPUTS}

Step 1 in the program is to establish general study data which will typically consist of the following items:

1. Throughput range to be considered.

2. Throughput increment for analysis.

7. Escallation costs .

3. Crude oil specific gravity.

8. Duties \& taxes.

4. Ship turnaround time.

9. Indirect costs.

5. Storage tank size.

10. Load factor of system.

6. Financial costs.

11. Contingency allowance.

12. Study currency.

Any other items which will remain constant for a11 sub-systems may be included in general study data.

Step 2 consists of 1isting the basic unit cost items which are required to establish both capital and annual costs of all sub-systems. Such items as dredging cost per cubic yard, and pier maintenance cost per year are included in this section. Assignment of unit costs can be simplified by relating all cost units of the same general type of material to a single basic unit. An example would be that of breakwater armor stone cost based on core rock cost times a multiplier. All unit costs are established to represent actual onsite prices.

\section{PORT SITE}

Step 3 requires that a port site be chosen that is associated with one of the candidate primary sub-systems for which quantity information has been supplied as data.

The general port site data of Step 4 concerns input items such as cost of land at the port site, cost of access, cost of utilities, and other similar items peculiar to the geographical location of the candidate site.

It is possible that several tank farm sites may be considered at each port site. It is probable however that an independent hand calculation will permit a single tank farm site to be selected for a given port without expanding the sub-system analysis. One of the most significant data 1tems assoc1ated with the storage tanks will be earth-moving and foundation preparation.

\section{PIPELINE}

To each port site will come several pipeline routes. Step 5 requires that one of these candidate plpeline routes be selected while Step 6 reads the quantity items such as pipeline length, miles of ditching in rock, and pumping horsepower at existing stations or by the addition of new stations along the Iine.

\section{SPECIFIC HARBOR DEVELOPMENT CONCEPTS}

At this point in the analysis a single port site on the coast is under consideration, as is one of several pipelines leading from the producing field to the port. At each port site several harbor development concepts have been carried through the preliminary design phase. For this study three 
harbor development schemes are considered for each candidate site, fixed piers with breakwater, sea berths, and mono-moorıngs. Due however to avai1able area or peculıar bathymetrıc conditions, some sites may not be adaptable to a11 three designs.

If the piers and breakwater scheme of Step 7 is to be considered, the throughput is inltialized in step 10 and then specific sub-system data is read in Step 11. Specific data consists of weather delay days or hours which result in port closure (this varies with natural protection at the site as noted in Figure 5 and with the operational limits of the mooring equipment included in the scheme), length and size of loading lines, pumping horsepower, and items such as dredging or removal of wrecks.

\section{Calculate Number of Berths}

The number of berths in a port must be such that the throughput can be loaded into tankers in the most economical manner. This calculation depends primarıly on tanker size, loading rate, throughput, and weather delay. observations at several ports have indlcated that sh1p arrivals and queuing can be accurately described by a Poisson distribution (References 3,4, and 5). Two methods may be used to determine what queuing delay is acceptable.

(1) The first method is to assume a maximum congestion figure of say, $5 \%$. This means that $5 \%$ of the time there are tankers walting for a berth. This figure is based on experience with tankers, however, it is rather unsatisfactory as it makes no allowance for variation in demurrage and berth costs.

(2) The alternative, and better, method 1s to make a benefit-cost analysis by comparing demurrage costs with the capital and annual costs of a new berth. Figure 8 shows the results of such an analysis. Here The Berth Unit Transportation Cost (BUTC, which is the unit cost of moving oil from the tank farm into the tanker) is plotted against throughput. For each number of berths there is optimum throughput giving a minimum BUTC shown by the vertical dotted line in Figure 8 . If the throughput is less than this optimum value, the BUTC rises since the berths are not being used at their optimum occupancy. If the throughput is greater, the BUTC again rises due to demurrage costs on waiting tankers, until the curve intersects the downward curve of the next higher number of berths. At this point the BUTC falls again and for this throughput a new berth should be added to the port. As the number of berths increases the BUTC for the optimum throughput decreases due to an increase in berth occupancy for the same delay time.

\section{TANK STORAGE CAPACITY}

The necessary volume of tank storage capacity in Step 13 is determined by the uncertainty of tanker arrivals and of discontinuities in pipeline delivery. The Poisson distribution calculation in Step 12 gives the probability of a given number of tankers arriving on a single day and the probability of consecutive days this number will arrive. If no tankers arrive for a number of days, then oll from the pipeline must be stored. If a large number of tankers arrive for several days, for example just after a storm, then there must be sufficient oil in storage to load these tankers even if flow through the pipeline has ceased. For a single crude it is usual to allow three-and-a-half days of storage for pipeline stoppages. The extreme 


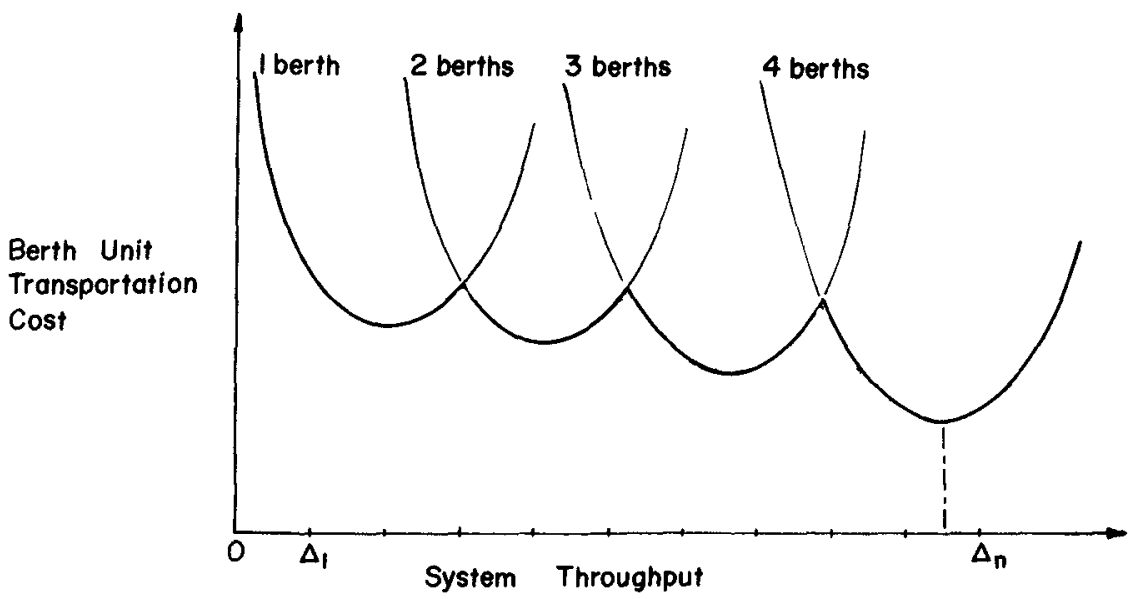

Figure 8

\section{BERTH UNIT TRANSPORTATION COST AGAINST SYSTEM THROUGHPUT}

storage requirement which is normally chosen 1 s such that on one or two days a year the storage capacity is inadequate.

After determination of the storage capacity and selection of a tank size, the tank farm area is computed. The tank size and helght and slope of dikes is general input data read $1 n$ Step 1 . The program also computes the amount of earth moving required to construct the dikes.

\section{CAPITAL AND ANNUAL COSTS}

After the number of berths and tank farm size has been determined in Steps 12 and 13, the program then returns to the input quantities associated with that particular increment of growth. Capital and annual costs are computed on the basis of the unit cost input data for the individual subsystem under consideration. These costs are then stored and the next increment of throughput is considered.

The program completes the analysis of each combination of pipeline and port development concept in Steps 17 through 23 .

\section{SELECTION OF PORT SITE}

After the computation of unit transportation costs for each increment of throughput, curves are plotted for each sub-system associated with a particular candidate port site. Figure 9 shows curves which typically result from the analysis of three alternate harbor concepts associated with a single candidate pipeline route. Since these curves are plotted from the UTC's computed only at the designed increments of throughput, they may be smoothed by decreasing the increment and thereby plotting a greater number of points.

The high initial UTC associated with the piers and breakwater design can be attributed largely to the high first cost of the breakwater. As throughput 


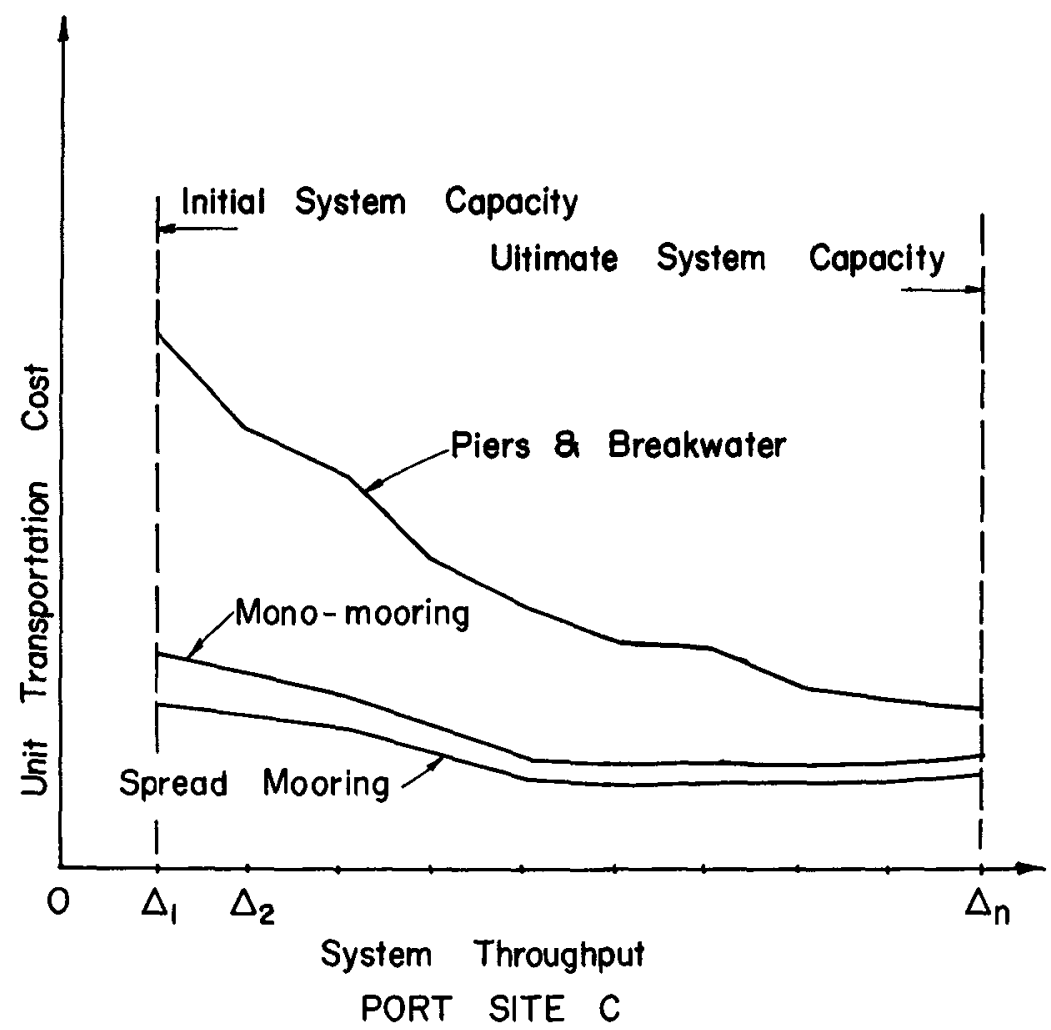

Figure 9

\section{ECONOMIC COMPARISON OF SITE DEVELOPMENT CONCEPTS}

increases, the UTC decreases reflecting the fewer weather delays and higher loading rates at fixed plers. Mono-moorings and spread moorings on the other hand show a lower initial UTC due to the fact that the only first cost associated with this type of port, other than the berth equipment, is the sma11 craft harbor. The UTC for these two types of designs remains nearly constant, or increases slightly, with increased throughput. The increased UTC results from longer loading lines to distant berths coupled with larger line sizes and increased loading pump horsepower. The shapes of these curves, however, reflect the local design, construction, and operational pecularities of the candidate port site.

Following the selection of a "best" development concept for each port 
site, a composite or sumnary graph may be plotted as shown in Figure 10. Th1s graph shows only the lowest UTC sub-system for each port site considered. The lowest UTC curve represents the selected site or sites and the associated harbor development concept.
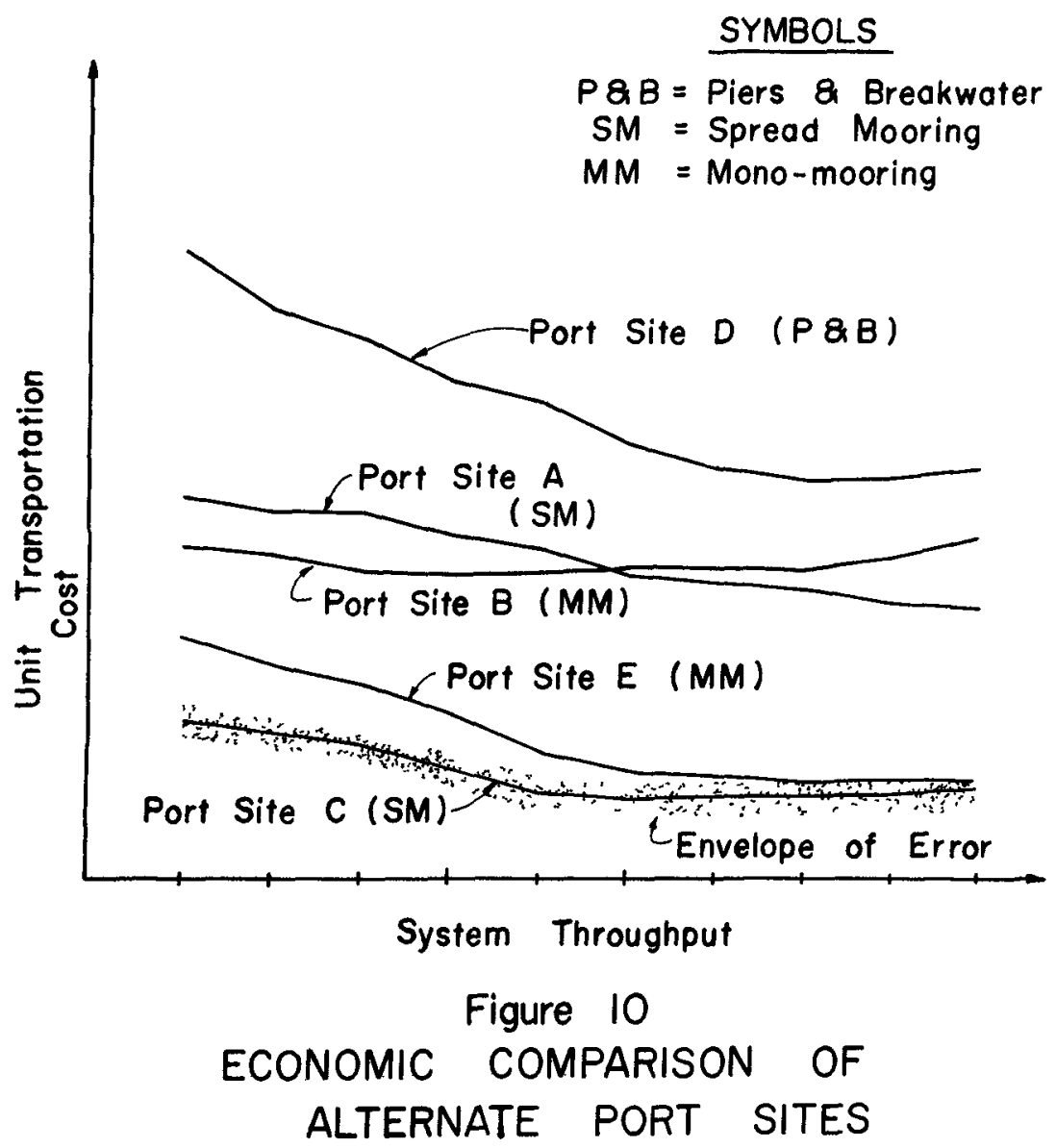

ACCURACY OF ANALYSIS

Early in the study the required accuracy of the economic analysis was established. That accuracy can be represented as an absolute or percentage error for each UTC. If that plus or minus error is plotted as an envelope on the lowest curve in Figure 10, it may enclose one or more other curves above it. Al1 curves which fall within this envelope must be considered to represent "best" sub-systems. In Figure 10 the Port Site E employing mono-moorings must be considered to be equal to the Port Site $C$ at higher throughputs. At this 
time economic, political, or social factors not expressed in the economic function may determine the port site. In the absence of such factors, an analysis of the type described in this paper, but performed on the basis of more thorough definition of all variables may permit a rational decision to be reached.

When the difference in unit transportation costs times the maximum annual throughput represents a capital cost less than the normal difference in construction bids, further refinement of the analysis is academic.

Occasionally two port sites, or alternate development concepts at one site, will change relative position as throughput is increased. This is shown in Figure 10 for Port Sites $A$ and $B$. In such a case additional economic factors must be considered to arrive at a rational decision.

\section{CONCLUSIONS}

(1) The systems approach to petroleum port site selection requires the engineer to recognize that port site selection is not an independent problem, but 1 s intimately related to adjacent parts of a total transportation system.

(2) The systems approach represents a method of accounting for a11 variables which affect the economics of shipping through a particular port site and results in economically defensible decisions.

(3) By the systems approach 1 is possible to determine the accuracy with which unit transportation cost is computed by means of the economic function so that excessive accuracy is not unjustifiably presumed.

\section{ACKNOWLEDGEMENT}

The authors wish to acknowledge the contrıbutions of P. M. Girardot and Nancy Jubien of Bechtel Corporation to the formulation of the digital computer adaptation of the method described herein. Permission by Bechtel Corporation to publish this material is appreciated.

\section{REFERENCES}

1. Formerly Chief Engıneer for Port and Coastal Development, Marine Department, P1peline Division, Bechtel Corporation, San Francisco, California.

2. Formerly Engineer, Marine Department, Plpeline Division, Bechtel Corporation, San Francisco, Calıfornia.

3. Fratar, T.J., A.S. Goodman, A.E. Brant. Prediction of maxımum practıcal berth occupancy. Proceedings of the American Society of Civil Engineers, Journal of the Waterways and Harbors Division, V.86, WW 2, June 1960: pp. $69-78$.

4. Plumlee, C.H. Optimum size seaport. Proceedings of the American Socrety of Civil Engineers, Journal of the Waterways and Harbors Division, V.92, WW 3, August 1966: pp. 1-24.

5. Mettam, J.D. Forecasting delays to ships in port, The Dock and Harbor Authority, London, V. XLVII, No. 558, April 1967: pp.380-382. 